\title{
Care Plans, Care Teams, and Quality of Life for People with Disabilities
}

\author{
Karen Donelan, SCD, EdM ${ }^{1,2}{ }^{0}$, Yuchiao Chang, $P h D^{3}$, Holly Matulewicz, $M A^{4}$, \\ Kimberly Warsett, MSW5 , Dennis Heaphy, MPH', and Lisa l. lezzoni, MD, MSc ${ }^{1,2}$
}

${ }^{1}$ Health Policy Research Center, The Mongan Institute, Massachusetts General Hospital Boston, MA, USA; ${ }^{2}$ Department of Medicine, Harvard Medical SchoolBoston, MA, USA; ${ }^{3}$ Division of General Internal Medicine, Massachusetts General HospitalBoston, MA, USA;

${ }^{4}$ MathematicaCambridge, MA, USA; ${ }^{5}$ Disability Policy ConsortiumBoston, MA, USA.

BACKGROUND: Massachusetts One Care was the first program approved among the Centers for Medicare \& Medicaid Financial Alignment Demonstrations for dually eligible beneficiaries. The only program focusing on dually eligible beneficiaries ages 21-64, One Care espouses an independent living philosophy for persons with disabilities. Researchers engaged with enrollees to develop new measures of enrollee quality of life and health to understand changes experienced in this new model of care.

OBJECTIVE: To examine whether enrollee knowledge of care plans and care teams predicts improvements in enrollee reported quality of life outcomes.

DESIGN AND PARTICIPANTS: We engaged with people with disabilities to develop and implement a longitudinal survey in One Care in Massachusetts. This analysis presents the self-reported outcomes of a panel of 315 enrollees' experiences with key plan features in Massachusetts One Care enrollees.

MAIN MEASURES: Knowledge of care plan, care team, and long-term services and supports (predictors); overall health, improved control, improved quality of health care, and improved hope for the future (outcomes).

KEY RESULTS: Enrollee-reported knowledge of a care plan and a care team over 2 years of enrollment in Massachusetts One Care was associated with increased odds of reporting more control over health (OR 2.58, CI 1.33, 5.03), improved health care quality (OR 3, CI 1.27, 7.06), and overall health (OR 2.07, CI 1.05, 4.08). Access to new services or equipment to live independently was associated with increased odds of reporting all four positive outcomes, notably for improved perceptions of hope (OR 2.33, CI 1.56, 5.39), overall health (OR 5.03, CI 2.44, 10.39), and improved quality of care (OR 4.22, CI 1.85 , 9.62).

CONCLUSION: Engagement of persons with disabilities in care teams and care planning, as well as quality measurement, can improve their experiences of quality of life and health care.

KEY WORDS: disability; consumer engagement; integrated care; patientreported outcomes; dual eligibility.

Electronic supplementary material The online version of this article (https://doi.org/10.1007/s11606-020-05908-w) contains supplementary material. which is available to authorized users.

Received June 21, 2019

Accepted May 4, 2020

Published online June 9, 2020
$\mathrm{J}$ Gen Intern Med 35(8):2274-80

DOI: $10.1007 / \mathrm{s} 11606-020-05908-\mathrm{w}$

(c) Society of General Internal Medicine 2020

\section{INTRODUCTION}

Approximately 11.7 million Americans were dually eligible for Medicare and Medicaid in 2016, and approximately $40 \%$ of those are adults under 65 years of age. Among those who are dually eligible and nonelderly are individuals with significant physical disability (SPD) or serious mental illness (SMI) whose per capita health care costs are significantly higher than other Medicare beneficiaries. ${ }^{1,2}$

In 2011, the Centers for Medicare \& Medicaid Innovation, in partnership with the Medicare-Medicaid Coordination Office, announced its Financial Alignment Demonstration for dually eligible beneficiaries. The demonstration offered two payment models: (1) managed fee-for-service and (2) a capitated model in which the Centers for Medicare \& Medicaid Services, a state, and participating health plans would enter "three-way contracts" that send prospective, blended payments to plans for providing comprehensive care to their dually eligible enrollees. ${ }^{3-6}$

The Massachusetts One Care program, using the capitated option, was the only program focusing solely on fully dually eligible beneficiaries ages 21 through $64 .^{7-9}$ When the initial three-way contract was executed, an estimated 105,000 Massachusetts residents were eligible for participation in 2013. Among these, $79 \%$ had a physical disability, $65 \%$ had a behavioral disability, and $14 \%$ had a developmental disability; $60 \%$ had more than one of these conditions. Collectively, this group accounted for more than $\$ 1$ billion in annual health care costs. A higher share of those costs was for long-term services and supports (LTSS) than for medical care. ${ }^{7}$ By February 2015, 17,763 people were enrolled in One Care. ${ }^{6}$ The threeway contract for Massachusetts One Care invoked the independent living philosophy, defined as "a philosophy which advocates for the availability of a wide range of services and options for maximizing self-reliance and self-determination in all of life's activities." ${ }^{.10}$ One Care aimed to integrate physical health care, behavioral health care, and new long-term services 
and supports. Key to care integration and coordination, according to the three-way contract, was the health plans' obligation to engage with enrollees in the formulation of Individual Care Plans working within Individualized Care Teams. ${ }^{10}$ The contract also includes guidance on the integration of LTSS services into care plans. ${ }^{10}$

As One Care launched in 2013, new measures developed by people with lived experiences of disability were absent. ${ }^{11-14}$ Disability rights advocates created the Disability Health Alliance to give voice to their goals for One Care, asking for improved measures of quality for eliciting enrollees' perceptions of their quality of health care and quality of life. ${ }^{11}$ As part of a study funded by the Patient-Centered Outcomes Research Institute, our team worked with key enrollee and community stakeholders to develop new measures.

This paper describes the experiences of a panel of One Care enrollees. We examined enrollees' knowledge of the care plan and care team, as well as their experience with long-term services and supports benefits. We also report enrollees' experience of their quality of life in One Care, including their health, perception of control over their health care, their hope for the future, and their overall quality of health care.

\section{METHODS}

\section{Source of Data}

The data reported here come from the Persons with Disability Quality Survey (PDQ-S) developed by our team through extensive collaboration with persons with lived experiences of disability. Persons with lived experience led the study as coprincipal investigators and comprised two different stakeholder research and consumer advisory groups. Persons with lived experience also recruited for focus groups, co-moderated focus groups, conducted key informant interviews and cognitive testing interviews, and analyzed data from all these efforts in collaboration with senior survey researchers. The survey instrument and its development have been described in further detail elsewhere. ${ }^{15-18}$

\section{Eligible Population, Sample Design, and Data Collection}

The population eligible for study were enrollees in the largest participating One Care health plan - a private, nonprofit plan with both employed and contracted providers covering 9 of 14 Massachusetts counties. Eighty-five percent of Massachusetts One Care enrollees participated in this plan.

Eligible enrollees were ages 21-64 with significant physical disability (SPD) or serious mental illness (SMI) who had been enrolled in One Care for a minimum of 6 months and were assigned a MassHealth rating category of $\mathrm{C} 2 \mathrm{~A}, \mathrm{C} 2 \mathrm{~B}, \mathrm{C} 3 \mathrm{~A}$, and $\mathrm{C} 3 \mathrm{~B}$. We excluded from eligibility people living in institutional care, and approximately 8000 One Care enrollees at this time were in rating category $\mathrm{C} 1$ and did not have the same needs as the $\mathrm{C} 2$ and $\mathrm{C} 3$ enrollees. Those included for our study were living in the community and had high behavioral health needs and/or high-cost long-term services and supports care needs related to a significant physical disability (as measured by the number of limitations in activities of daily living). ${ }^{6,10}$

We selected enrollees from 27 primary care practices, each of which cared for 50 or more One Care members who met study participation criteria. Collectively these practices accounted for approximately $75 \%$ of then-current enrollees in the plan.

We administered the PDQ-S twice, first in the fall of 2015 (wave 1) and again 1 year later in the fall of 2016 (wave 2). Outreach to sample members began with validating mailing addresses and telephone numbers; in week 1 of the field period, a survey invitation letter was sent via first-class mail. In week 2 , contact included a postcard reminder, email invitation to those for whom emails were available, and an invitation message via voicemail. ${ }^{1}$ When the survey team reached a sample member directly, an interviewer proceeded with the interview by telephone. The questionnaire was mailed to all nonresponders in week 3 , followed by a postcard and an email reminder in week 4. Professional, trained interviewers called nonresponders from weeks 5 through 12 . Postcard reminders were sent to all pending non-refusal cases in weeks 8 and 10. All study mailings included a toll-free number for sample members to call with questions or to complete an interview by telephone.

Using this mixed mode approach to contact, participants had the option of completing the survey on paper, online, by telephone, or even by personal interview face-to-face (no one utilized the face to face option). Interviewers were available by telephone or in person to conduct interviews in English, Spanish, or American Sign Language. Seventy percent of respondents completed the survey by telephone, $25 \%$ by mail, and $5 \%$ online. Proxy responses were discouraged and ultimately completed for only 2 respondents, who would not have been able to participate otherwise. Respondents were paid up to $\$ 15$ per person to complete each survey.

The baseline interviews for the study (wave 1) were conducted in September and October, 2015. We randomly selected 720 individuals from the 3483 eligible enrollees, selecting equal numbers of persons per primary care practice (in one large practice we selected twice as many persons). One year later, in September and October 2016 we conducted follow-up interviews of One Care enrollees in the same practices (wave 2). We established that within study practices, 600 of the 720 selected in wave 1 were living and still enrolled in One Care as of April 2016. Four hundred fifty-one enrollees completed wave 1 , and 426 completed wave 2 . For the analyses reported in this paper, we used paired data from the 315 enrollees who completed both waves of the survey.

\footnotetext{
${ }^{1}$ We sent materials in Spanish to all people whose language was flagged as Spanish in CCA records. The advance letter was sent in both English and Spanish.
} 
Table 1 Sociodemographic Characteristics at Wave 1, by Disability Status

\begin{tabular}{|c|c|c|c|c|}
\hline \multirow[t]{2}{*}{ Sociodemographic characteristics } & \multirow{2}{*}{$\frac{\operatorname{ALL}(n=315)}{\% *}$} & \multirow{2}{*}{$\frac{\text { Significant physical disability }}{\% *}$} & \multirow{2}{*}{$\begin{array}{l}\text { Serious mental illness } \\
\% *\end{array}$} & \multirow[t]{2}{*}{$p$ value } \\
\hline & & & & \\
\hline \multicolumn{5}{|l|}{ Age } \\
\hline$<40$ years old & 20.0 & 26.8 & 15.3 & \multirow{4}{*}{0.18} \\
\hline $40-49$ years old & 18.2 & 18.8 & 17.8 & \\
\hline $50-59$ years old & 45.9 & 40.2 & 49.7 & \\
\hline $60+$ years old & 16.0 & 14.2 & 17.2 & \\
\hline \multicolumn{5}{|l|}{ Gender } \\
\hline Male & 54.8 & 50.4 & 57.9 & \multirow[t]{2}{*}{0.27} \\
\hline Female & 45.2 & 49.6 & 42.1 & \\
\hline \multicolumn{5}{|l|}{ Race/ethnicity } \\
\hline White & 39.2 & 35.6 & 41.7 & \multirow{4}{*}{0.73} \\
\hline Black & 18.3 & 18.0 & 18.5 & \\
\hline Hispanic & 33.0 & 37.1 & 30.2 & \\
\hline Other & 9.5 & 9.3 & 9.6 & \\
\hline \multicolumn{5}{|l|}{ Language version of PDQ-S } \\
\hline English & 84.7 & 90.0 & 81.0 & \multirow[t]{2}{*}{0.39} \\
\hline Spanish & 15.3 & 10.0 & 19.0 & \\
\hline \multicolumn{5}{|l|}{ Education } \\
\hline$<$ high school & 30.0 & 36.0 & 26.0 & \multirow[t]{3}{*}{0.81} \\
\hline High school or GED & 30.5 & 25.6 & 33.8 & \\
\hline More than high school & 36.4 & 35.6 & 37.0 & \\
\hline \multicolumn{5}{|l|}{ One Care care coordination } \\
\hline Reports care team & 62.3 & 53.4 & 68.4 & 0.07 \\
\hline Reports care plan & 56.7 & 50.5 & 61.0 & 0.20 \\
\hline \multicolumn{5}{|l|}{ Current living arrangement } \\
\hline Lives with others & 59.2 & 58.7 & 59.5 & \multirow{2}{*}{0.42} \\
\hline Living alone & 40.8 & 41.3 & 40.5 & \\
\hline \multicolumn{5}{|c|}{ Experienced homelessness in last 6 months } \\
\hline Yes & 8.0 & 9.2 & 7.2 & \multirow[t]{2}{*}{0.06} \\
\hline No & 89.4 & 86.6 & 91.3 & \\
\hline
\end{tabular}

${ }^{a}$ Weighted percent

Source: authors' analysis of the Persons with Disability Quality Survey, 2018

\section{Persons with Disabilities Quality Survey}

We developed the PDQ-S to assess quality of life, health, and health care in One Care from the perspective of enrollees with SPD or SMI. Survey domains included measures on independence and quality of life, experience of primary care services, knowledge and use of One Care services, use of LTSS services, and experience with One Care plan features. ${ }^{16}$ The full questionnaire is shown in the appendix.

Most respondents completed the PDQ-S in 15 to $20 \mathrm{~min}$. Questionnaire domains include daily life in the community, expectations for the future, care plans and care teams, relationships with primary care providers (PCPs), and LTSS, as well as overall health and quality of health care.

Table 3 Association Between Services that Were Newly Offered in One Care and Reported Access to Services and Equipment Needed to Live Independently

\begin{tabular}{|c|c|c|}
\hline \multirow[t]{2}{*}{ \% reported "Better now" (weighted) } & \multicolumn{2}{|c|}{$\begin{array}{l}\text { Have you been offered new } \\
\text { services/help with }(n=315)\end{array}$} \\
\hline & No & Yes \\
\hline Housing? & 33.2 & $57.3 * * *$ \\
\hline Buying healthy food? (SPD group) & 37.2 & $53.2 *$ \\
\hline Transportation for nonmedical appointments? & 28.2 & $57.2 * * *$ \\
\hline The cost of utilities, such as heat, electricity, telephone? & 38.2 & 51 \\
\hline Getting new equipment or technology you need? & 38 & 49.1 \\
\hline Dental care? & 33.1 & $48^{*}$ \\
\hline Setting goals for the future? & 25.1 & $55.5 * * *$ \\
\hline Helping you organize your life to do the things you want to do? & 25.6 & $59 * * *$ \\
\hline Addressing feelings of isolation and loneliness? & 29.9 & $54.6 * * *$ \\
\hline Learning your rights about grievance procedures for services not received or denied? (SPD group) & 36.9 & $53.4 *$ \\
\hline Mental health recovery? (SMI group) & 31.9 & $51.5 * *$ \\
\hline Substance use or sobriety? & 43.7 & 44.8 \\
\hline
\end{tabular}

$* p<0.05$

$* * p<0.01$

$* * * p<0.001$

Source: authors' analysis of the Persons with Disability Quality Survey, 2018 


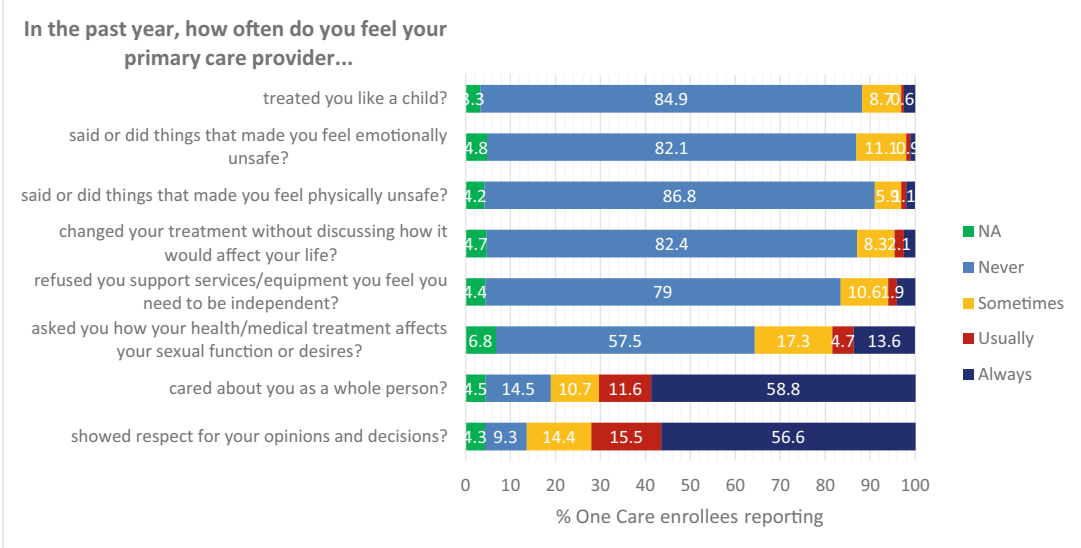

Figure 1 Enrollee perceptions of primary care quality. Notes and sources: authors' analysis of the Persons with Disabilities Quality Survey, 2018.

The Partners Healthcare Human Research Committee approved all aspects of this study.

\begin{abstract}
ANALYSIS
For all analyses, the survey data were weighted to adjust for non-response by known characteristics of the population, including age, type of disability, gender, and race/ethnicity. We also created a weight to adjust for our selection of the same number of enrollees from differently sized practices. Without this weighting our survey findings would overrepresent people in small practices and underrepresent those in larger practices. All percentages are weighted in all tables and figures. We also used statistical adjustments for multiple comparisons within the data. For Table 1, we compared participant characteristics at baseline using chi-square tests. For Table 3, in the comparisons of wave 1 and wave 2 responses, we also used chi-square tests and considered a two-sided $p$ value of 0.05 or less statistically significant. Data in Figures 1 and 2 are descriptive; these estimates have a margin of error of approximately $\pm 4 \%$.
\end{abstract}

\section{Multivariate Analysis}

Independent variables. Our key independent variables - having a care plan, a care team, and accessing new LTSS services to live independently-were measured directly in the survey by self-report; responses were binary (yes/no).

Dependent variables. There are four outcomes for the multivariate analyses. We conducted ordinal regression models for the net change over 2 years in four key outcomes reported by enrollee: (1) feelings of hope about the future, (2) perceived amount of control over health care, (3) health status, and (4) the quality of the health care received. In each year, respondents could say their life or health was better, the same, or worse; over 2 years, there were 9 possible combinations (better-better, better-same, better-worse, and so on). We sought to measure a net positive change, a net negative change, or no change. We created a new composite variable that would capture the net change over the 2-year period of enrollees' participation in One Care (and in our study). We created an

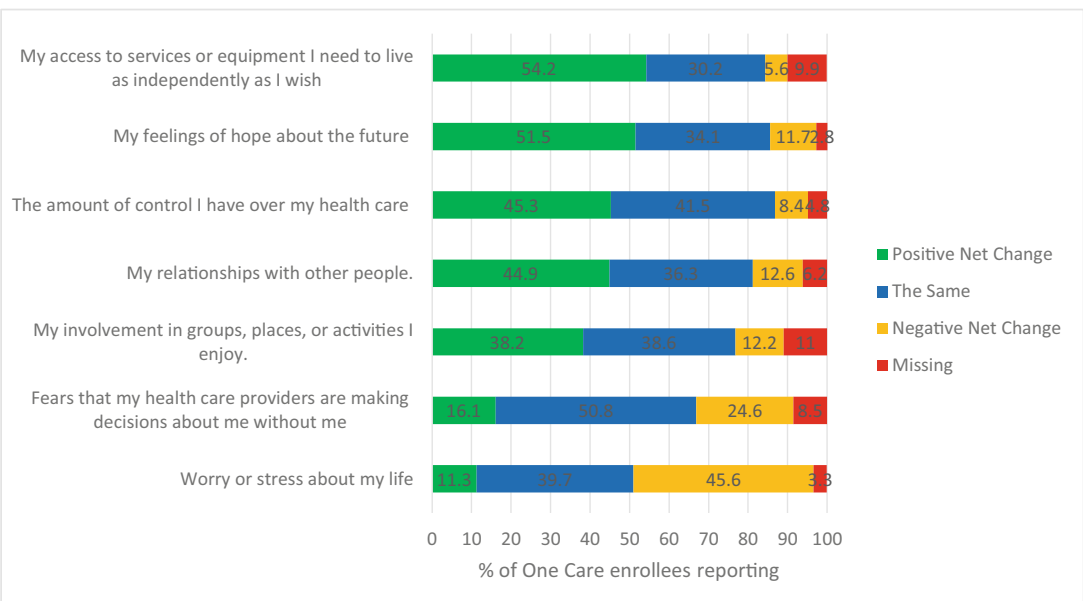

Figure 2 Reported net change in quality of life and health measures. Notes and sources: authors' analysis of the Persons with Disabilities Quality Survey, 2018. 
ordered variable with 3 codes: positive, the same, and negative, and coded responses accordingly. We coded each response as positive, the same, and negative. We coded a net change of "positive" if participants reported improvement in both years or improvement in either the first or second year and no change in the other year. We coded a net change of "the same" (no change) if participants responded "the same" in both years or responded that one year was positive and one was negative. Finally, we coded a net change of "negative" if participants reported "the same" in one year and worse in the other or worse in both years.

We presented the cumulative odds ratios of a more positive outcome $\mathrm{v}$ a less positive outcome for having care plans and care teams, increased access to needed services to live independently, and type of disability, controlling for age, gender, race, education, marital status, and living situation.

We conducted all analyses using SAS Version 9.4 (SAS Institute, Cary, NC) survey procedures to account for survey sampling structure and sampling weights.

\section{RESULTS}

The response rate among all respondents in wave 1 was $62 \%$ $(n=451)$; the response rate in wave 2 among the wave 1 respondents was $70 \%$. Among the subset of 315 enrollees who completed both survey waves, 129 (41\%) of whom have SPD and $186(59 \%)$ had SMI in wave 1. Self-reported sociodemographic characteristics are shown in Table 1 by disability group. Sixty-two percent of respondents were $\geq 50$ years old, about $55 \%$ were male, and approximately $40 \%$ were white. In wave $1,44 \%$ of respondents indicated they had both a care team and a care plan, $9.4 \%$ had only a care team, $6.5 \%$ had only a care plan, and $40.1 \%$ reported neither. There were no differences in enrollee characteristics by disability type.
Respondent reports of the frequency of experiences of several aspects of disability-related quality of primary care did not change significantly from wave 1 to wave 2 . Figure 1 shows responses at wave 1. For three measures, increased frequency indicates higher quality care (showed respect, "cared about you as a whole person," asked about impact of treatment on sexual function or desires). Nearly $40 \%$ of respondents indicated that their PCPs showed respect or "cared about them as a whole person" less than always; 57\% of respondents said their PCPs "never" asked about their sexual health. For the remaining measures, decreased frequency indicates higher quality care. For each, although about $80 \%$ or more indicated they "never" happened, $10-15 \%$ said they happened at least sometimes. Nearly $17 \%$ reported that their provider refused "needed services or equipment that would help them live independently."

A majority of enrollees indicated positive changes in measures of quality of life and independence across the 2 years of their enrollment (Figure 2). Increases, improvements, or changes for the better are denoted as "positive" changes. For 2 items - worry or stress about life, fears providers are "making treatment decisions about me" without the enrollee's involvement - a "positive" change or increase denotes lower quality of life; for all other items, a "positive" change indicates higher quality of life.

Finally, we explored the impact of care plans and care teams and access to services on several key outcomes (hope, control, health, health care) in multivariate regression models, controlling for type of disability and several other sociodemographic factors. Table 2 shows the main effects of the regression analyses. Having both a care plan and care team in both years of enrollment was associated with increased odds of reporting more control over health (OR 2.58, CI 1.33, 5.03), improved health care quality (OR 3, CI 1.27, 7.06), and overall health (OR 2.07, CI 1.05, 4.08). Access to new services or equipment to live independently was associated with increased odds of

Table 2 Multivariate Regression Models of the Relationship Between Enrollee Knowledge of Care Plans, Teams, and LTSS on the Health of One Care Enrollees

\begin{tabular}{|c|c|c|c|c|}
\hline & $\begin{array}{l}\text { Feelings of hope for the } \\
\text { future }\end{array}$ & $\begin{array}{l}\text { Amount of control over health } \\
\text { care }\end{array}$ & $\begin{array}{l}\text { Quality of health } \\
\text { care }\end{array}$ & $\begin{array}{l}\text { Overall } \\
\text { health }\end{array}$ \\
\hline $\begin{array}{l}\text { Predictor } \\
\text { Care team/care plan }\end{array}$ & $\mathrm{OR}^{\dagger}$ & $\mathrm{OR}^{\dagger}$ & $\mathrm{OR}^{\dagger}$ & $\mathrm{OR}^{\dagger}$ \\
\hline Having both in both years & 1.37 & $2.58 * *$ & $3.00 * *$ & $2.07 *$ \\
\hline $\begin{array}{l}\text { Outcome improved in } 2 \text { nd } \\
\text { year }\end{array}$ & 0.76 & 0.98 & 1.11 & 1.10 \\
\hline Outcome worse in 2 nd year & ref & & & \\
\hline \multicolumn{5}{|c|}{ Access to services or equipment to live independently } \\
\hline $\begin{array}{l}\text { Better now } \\
\text { Worse now } \\
\text { The same }\end{array}$ & $\begin{array}{l}2.90 * * * \\
0.34 \\
\text { ref }\end{array}$ & $\begin{array}{l}2.33^{* *} \\
0.86\end{array}$ & $\begin{array}{l}4.22 * * * \\
0.20 * *\end{array}$ & $\begin{array}{l}5.03 * * \\
0.22 * *\end{array}$ \\
\hline \multicolumn{5}{|l|}{ Disability } \\
\hline $\begin{array}{l}\text { Significant physical disability } \\
\text { Severe mental illness }\end{array}$ & $\begin{array}{l}0.97 \\
\text { ref }\end{array}$ & $1.80 *$ & 1.12 & 0.89 \\
\hline
\end{tabular}

$* p<0.05$

$* * p<0.01$

$* * * p<0.001$

†Adjusted odds ratio of a more positive outcome versus a less positive outcome, controlling for age, gender, race, education, marital status, and living situation. 
reporting all four positive outcomes, notably for improved perceptions of hope (OR 2.33, CI 1.56, 5.39), overall health (OR 5.03, CI 2.44, 10.39), and improved quality of care (OR 4.22 , CI 1.85, 9.62). Compared with those who reported similar access at year 2, the perception that access to these services was worse was significantly associated with negative reported outcomes, whereas the perception that access to these services was better was significantly associated with positive reported outcomes.

Several LTSS services that were covered in One Care were significantly associated over the 2 years with the perception of better "access to services or equipment needed to live independently." These services include help with organization and life skills, support with social determinants of health, transportation, and mental health and dental care access (Table 3 ).

\section{DISCUSSION}

This analysis of the experience of 315 One Care enrollees in the first 2 years of the One Care demonstration underscores the importance of care plans, care teams, and access to LTSS services for enrollees who live with significant physical disability or serious mental illness. Our hypothesis for these analyses was that enrollee reporting of having these features would signal fuller engagement in their own care, thereby making it more likely that the enrollee would experience desired outcomes of hope for the future, control over their own health, and a sense of improved health and quality of health care.

Key findings in this study confirmed these hypotheses in the lives of people with SPD and SMI. Individualized Care Teams, Individualized Care Plans, and LTSS services are not new concepts: their integration into the three-way contractual agreement among CMS, the Commonwealth of Massachusetts, and health plans made explicit that beyond being mechanisms to enhance care integration and coordination, these features were required to assure the engagement and inclusion of enrollees in the determination of their own health care arrangements. ${ }^{9}, 10$

Indeed, in this analysis, enrollees' knowledge of a care plan and care team, over 2 years of enrollment, significantly improved the likelihood that enrollees would perceive improved health, quality of health care, and - importantly - an increased feeling of control over their health decisions.

LTSS, the home- and community-based items and services persons need to live safely and comfortably in their homes and to participate in community life, would address social determinants and help achieve the enrollees' own stated goals for social interaction. The highly significant results in our multivariate analyses for several outcomes - increased feelings of hope, perceptions of improved overall health, increased quality of health care, and increased control-underscore the enrollees' experiences that enhanced "access to new services to live independently" will have positive health and life benefits for this population. It is of note that in the model predicting increased feelings of hope for the future, the care team and care plan were not significant predictors, but access to new services to live independently was. Those new services that were most associated with improved access to new services for independent living for people with SPD and SMI in One Care were assistance with healthy food access, housing, mental health recovery, dental health, assistance with goal setting, organizational skills, transportation for nonmedical reasons, services to reduce isolation, and education about rights to grievances.

The health services and health policy literature is currently brimming with proposals for care transformation to meet the health and social care needs of people with serious mental illness or significant physical disabilities. Many of these discussions appropriately focus on how the system will make these arrangements and enhance the quality of life of stressed, burned-out health professionals working in teams. ${ }^{19-21} \mathrm{Al}-$ though it is often assumed that the discussion of care teams includes the patient, the literature on the experience of patients within differently configured care teams is sparse. ${ }^{22}$

One Care has not been an unqualified success. Early experience in Massachusetts showed that plans struggled financially under initial capitation levels; one major plan dropped out after the first year. ${ }^{23}$ Further adjustments have been made to stabilize the program. The number of people in One Care in Massachusetts still represents a small share of dually eligible enrollees in the state, ${ }^{24}$ nationally, the program has not enrolled people at the rates initially expected. ${ }^{25}$

This study has several limitations. First, our data are observational; no causation is implied. Our surveys were conducted with a subset of One Care enrollees in one large plan and in physician practices with more than 50 enrollees. Experiences reported here may not be representative across practices and across plans, especially outside Massachusetts. Also, we surveyed people in English, Spanish, and American Sign Language and excluded people who spoke other languages. We did not reach all attempted enrollees and cannot control for all non-response bias. Finally, these are self-reported data, limited to the knowledge and reports of enrollees who may not be in a position to observe some aspects of how practices organize their care.

Some researchers have questioned whether people with serious disabilities can validly report experiences in health plans or health care. ${ }^{26}$ In our opinion, the design and conduct of this research by persons with lived experience of serious mental illness and significant physical disability set the stage for a data collection process that led to an extraordinarily high rate of response to the surveys. As noted in the methods, this work was guided by the principle that to improve measurement, key decisions in the research were made in partnership among the persons most knowledgeable and experienced. The high rate of response to the surveys reflects the strength of the design and the engagement of enrollees in creating meaningful measures. More than two-thirds of enrollees recognized that this One Care plan had the key required features of care plans, 
care teams, and LTSS. These mechanisms were the levers intended in the Massachusetts One Care contract to assure integration of all health-related services for enrollees. Enrollees who reported these features in their plans experienced more hope, a greater sense of control, and improved health and health care over the 2 years of enrollment studied.

Corresponding Author: Karen Donelan, ScD, EdM; Health Policy Research Center, The Mongan Institute, Massachusetts General Hospital Boston, MA, USA (e-mail: kdonelan@partners.org).

Funding information This work was supported through a PatientCentered Outcomes Research Institute (PCORI) Award (IHS-130601424).

\section{Compliance with ethical standards:}

The Partners Healthcare Human Research Committee approved all aspects of this study

Conflict of interest: From 2007 to July 6, 2017, Dr. Iezzoni served voluntarily (without pay) on the Board of Directors of the nonprofit One Care health plan that participated in the project. One of the authors (name withheld to protect privacy) is an enrollee in One Care.

Disclaimer: All statements in this report, including its findings and conclusions, are solely those of the authors and do not necessarily represent the views of the Patient-Centered Outcomes Research Institute, its Board of Governors, or its Methodology Committee.

\section{REFERENCES}

1. Meyer $\mathbf{H}$. The coming experiments in integrating and coordinating care for "dual eligibles." Health Aff. 2012;31(6):1151-1155.

2. CMS Medicare-Medicaid Coordination Office. Data Analysis Brief: Medicare-Medicaid Dual Enrollment 2006 through 2016; 2017. Available at: https://www.cms.gov/Medicare-Medicaid-Coordination/Medicareand-Medicaid-Coordination/Medicare-Medicaid-Coordination-Office/ DataStatisticalResources/Downloads/Eleven-YearEver-EnrolledTrendsReport_2006-2016.pdf. Accessed Jan 15, 2020.

3. Kaiser Commission on Medicaid and the Uninsured. Financial and administrative alignment demonstrations for dual eligible beneficiaries compared: States with memoranda of understanding approved by CMS; 2013. Available at: https://www.kff.org/search/?s=financial+and+administrative+alignment+demonstrations+for+dual+eligible+beneficiaries+compared:+states+with+memoranda+of+understanding+approved+by+CMS, Accessed Jan 16, 2020.

4. Kaiser Commission on Medicaid and the Uninsured. Explaining the state integrated care and financial alignment demonstrations for dually eligible beneficiaries; 2012. Available at: https://www.kff.org/medicaid/issuebrief/explaining-the-state-integrated-care-and-financial/. Published 2012. Accessed Jan 15, 2020.

5. Kaiser Commission on Medicaid and the Uninsured. Development of the financial alignment demonstrations for dual eligible beneficiaries: Perspectives from national and state disability stakeholders; 2013. Available at: https://www.kff.org/medicaid/issue-brief/development-of-the-financialalignment-demonstrations-for-dual-eligible-beneficiaries-perspectivesfrom-national-and-state-disability-stakeholders/. Accessed Jan 15, 2020.

6. Barry C, Riedel L, Busch A, Huskamp H. Early Insights from One Care: Massachusetts' Demonstration to Integrate Care and Align Financing for Dual Eligible Beneficiaries. Issue Brief. Henry J. Kaiser Family Foundation; 2015. Available at: http://kff.org/report-section/early-insights-from-onecare-massachusetts-issue-brief-8725/. Accessed Jan 15, 2020.

7. Davidson EB, Dreyfus T. Dual eligibles in Massachusetts: A Profile of Health Care Services and Spending for Non-elderly Adults in Both Medicare and Medicaid. Massachusetts Medicaid Policy Institute; 2011.
Available at: http://bluecrossmafoundation.org/sites/default/files/ MMPI Duals Chart Pack_0.pdf. Accessed January 15, 2020.

8. Kaiser Commission on Medicaid and the Uninsured. Massachusetts' demonstration to integrate care and align financing for dual eligible beneficiaries. Issue brief; 2012. Available at: https://www.kff.org/medicaid/issue-brief/massachusetts-demonstration-to-integrate-care-andalign/. Accessed Jan 15, 2020.

9. Klein S, Hostetter M, McCarthy D. The "One Care" Program at Commonwealth Care Alliance: Partnering with Medicare and Medicaid to Improve Care for Nonelderly Dual Eligibles. Commonwealth Fund; 2016. Available at http://www.commonwealthfund.org/publications/case-studies/2016/ dec/commonwealth-care-alliance. Accessed Jan 15, 2020.

10. U.S. Department of Health and Human Services, Centers for Medicare \& Medicaid Services. Three Way Contract for Capitated Model, in Partnership with the Commonwealth of Massachusetts and Commonwealth Care Alliance,Inc., Fallon Community Health Plan, Network Health LLC; July 2013. Available at: https://www.mass.gov/files/documents/2017/ 08/31/contract-for-one-care-plans.pdf. Accessed Jan 15, 2020.

11. National Quality Forum. Advancing Person-Centered Care for Dual Eligible Beneficiaries through Performance Measurement: 2015 Recommendations from the Measure Applications Partnership. Washington, DC: National Quality Forum; 2015.

12. Disability Rights Education and Defense Fund. A Guide for Advocates Identifying and Selecting Long-Term Services and Supports Outcome Measures; 2013. Available at: http://dredf.org/2013-documents/GuideLTSS-Outcome-Measures.pdf. Accessed Jan 15, 2020.

13. Lawthers AG, Pransky GS, Peterson LE, Himmelstein JH. Rethinking quality in the context of persons with disability. Int $\mathrm{J}$ Qual Health Care. 2003;15(4):287-299.

14. Iezzoni L. Developing Quality of Care Measures for People with Disabilities: Summary of Expert Meeting. AHRQ Publication No. 100103. Rockville: Agency for Healthcare Research and Quality; 2010.

15. Iezzoni LI, Marsella SA, Lopinsky T, Heaphy D, Warsett KS. Do prominent quality measurement surveys capture the concerns of persons with disability? Disabil Health J. 2017;10(2):222-230.

16. Iezzoni LI, Matulewicz H, Marsella SA, Warsett Ks, Heaphy D, Donelan K. Collaborative design of a health care experience survey for persons with disability. Disabil Health J. 2017;10(2):231-239.

17. Iezzoni LI, Heaphy D, Warsett KS, Marsella SA. Description of YESHealth: A consumer-directed intervention in a randomized trial of methods to improve quality of care for persons with disability. Disabil Heal J. 2018;11(4):545-554

18. Iezzoni LI, Chang Y, Matulewicz H, Warsett KS, Heaphy D, Donelan K. Health plan enrollees with disability informing primary care practices and providers about their quality of care: A randomized trial. Disabil Health $\mathrm{J}$. 2018;11(4):537-544.

19. Sinsky CA, Willard-Grace R, Schutzbank AM, Sinsky TA, Margolius D, Bodenheimer T. In search of joy in practice: A report of 23 highfunctioning primary care practices. Ann. Fam. Med. 2013;11(3):272-278.

20. Ghorob A, Bodenheimer T. Sharing the care to improve access to primary care. NEJM. 2012;366:1955-1957.

21. Shanafelt TD, Noseworthy J. Executive leadership and physician wellbeing. Mayo Clinic Proceedings. 2017;92(1):129-146.

22. Day J, Scammon DL, Kim J, Sheets-Mervis A, Day R, Tomoaia-Cotisel A, Waitzman NJ, Magill MK. Quality, satisfaction, and financial efficiency associated with elements of primary care practice transformation: Preliminary findings. Ann Fam Med. 2013;11(Suppl.1):S50-S59.

23. Gattine EC, Fralich J, Booth M, Greene AM, Anderson WL, Morley M, Toth M, Wang J, Wiener JM, Kaiser D, Chepaitis A. Financial Alignment Initiative Annual Report. One Care: MassHealth plus Medicare, RTI International; 2016.

24. Executive Office of Health and Human Services. One Care: January 2018 Enrollment Report: MassHealth Demonstration to Integrate Care for Dual Eligibles, Monthly Enrollment Report. January 2018. Available at: https://www.mass.gov/files/documents/2018/02/07/January\%202018\%200ne\%20Care\%20Enrollment\%20Report\%20FINAL.pdf. Accessed Jan 15, 2020.

25. Grabowski DC, Joyce NR, McGuire TG, Frank RG. Passive enrollment of dual-eligible beneficiaries into Medicare and Medicaid managed care has not met expectations. Health Aff. 2017;36(5):846-854.

26. Iezzoni LI. Explicit disability bias in peer review. Med Care. 2018;56(4):277-278

Publisher's Note: Springer Nature remains neutral with regard to jurisdictional claims in published maps and institutional affiliations. 